\title{
平面熱応力問題の電気的相似測定法についで
}

\author{
荻原保右衛門** 黑田訓起***田口 久 夫****
}

\section{The Use of Electrical Simulator for Measurement \\ of Thermoelastic Plane Surface}

by

\author{
Yasuemon OGIWARA \\ (Okayama College of Science, Okayama) \\ Norioki KURODA \\ (Toshin Steel Co., Ltd., Tokyo) \\ and Hisao TAGUTi \\ (Toshin Steel Co., Ltd., Himeji Steel Works, Himeji)
}

It is generally known that the biharmonic equation can be solved upon mutual analogy in the use of resistance simulator, and that the problems concerning the equations for thermoelastic two-dimensional surface in the multiply connected regions will be divided between Laplace's and Poisson's equations.

In the present paper it is demonstrated theoretically that the problems concerning the equations of thermoelastic two dimensional surface in the multiply connected regions can be solved upon mutual analogy in the use of resistance simulator, and for its verification the estimation of stress distribution has accordingly been made in the circular ingot mould.

The agreement of the measurement made by using resistance simulator with the theoretical values is found to have been sufficiently established for practical purposes. Although there is some difficulty in setting boundary conditions when this method is used, and in spite of the errors that inevitably arise in numerical differentiation of stress function, this method is commendable as being efficient for estimation of thermal stress distributed in the multiply connected regions.

(Received Nov. 19, 1970)

\section{1 緒言}

任意形状の重複連結領域の平面熱応力問題を理論的 に解析することは困難である。しかし設計上の立場か らいえば，理論的でなくともなんらかの方法で，実用 上じ的５ぶんな精度を有する解が得られればじゅうぶ んであると思われる。. P.J. Palmer, S.C. Redshaw は重調和関数が抵抗回路網によって, 近似的に相似解 析せられろることに基ついて，平板の引張りおよび曲 げを抵抗回路網によって相似解析しているが，平面熱 応力問題の基礎式が重調和関数と関係があることから, 平面熱応力問題も抵抗回路網によって相似解析せられ らるはすである。

本報告ではまず任意形状の重複連結領域の平面熱応 力問題を解くための基礎式について述べ，次にこの式

* 原稿受理 昭和45年11月19日

** 正会員阊山理科大学岡山市宿、

*** 正 会員 東伸製鋼(株) 東京都千代田区丸の内

***** 正会員 東伸製鋼(株)姫路製鋼所 姫路市飾磨区細江
が抵抗回路網によって電気的に相似解析せられらるこ とを説明し，その計算例として解析した丸型鋼塊用鋳 型の造塊時に発生する熱応力を理論解と比較した。

$$
2 \text { 基 礎 式 }
$$

平面熱応力問題の応力成分は応力関数 $\chi$ を用いると 次のように表わされる。

$$
\sigma_{x}=\frac{\partial^{2} x}{\partial y^{2}}, \quad \partial y=\frac{\partial^{2} \chi}{\partial x^{2}}, \quad \tau_{x y}=-\frac{\partial^{2} \chi}{\partial x \partial y}
$$

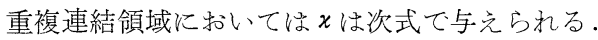

$$
x=x_{0}+\sum_{\imath=1}^{n}\left(C^{\prime}{ }_{1 \imath} x_{1 \imath}+C_{2 \imath}^{\prime} x_{2 \imath}+C^{\prime}{ }_{3 \imath} x_{3 \imath}\right)
$$

この $x_{0}, x_{1 \imath}, x_{2 \imath} x_{3 \imath}, C_{1 \imath}^{\prime}, C_{2 \imath}^{\prime}, C_{3 \imath}^{\prime}$ は次の条件て定 めら机る。

(a) 任意の点について基礎式は

$$
\nabla^{4}\left(x_{0}, x_{1 \imath}, x_{2 \imath}, x_{3 \imath}\right)=\left(-E A \nabla^{2} T, 0,0,0\right)
$$

ここで $\nabla^{2}=\partial^{2} / \partial x^{2}+\partial^{2} / \partial y^{2}, E=$ 縱弾性係数, $T=$ 温 度分布関数, $A=\alpha$ : 平面応力の場合, $A=\alpha /(1-\sigma)$ :

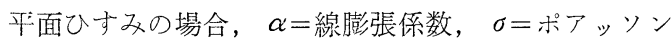




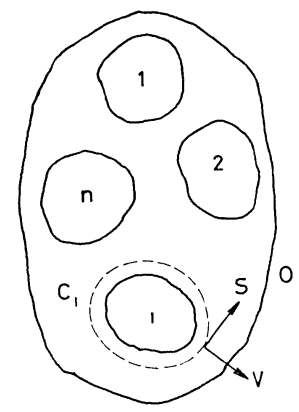

F1g. 1. Multıply-connected region.

比

(b) 境界条件 有限重複連結領域に対して, Fig. 1 のように境界に適当に番号 $0,1,2, \cdots \cdots, n$ をつけ るとき, 第っ境界上の任意の点 $P$ 。で, 境界の接線と 一致しない任意の方向を $\lambda$ として，次の式で与えられ る.

$$
\begin{gathered}
\left(x_{0}\right) P_{\jmath}=\left(\frac{\partial x_{0}}{\partial \lambda}\right)_{P_{\jmath}}=0 \\
\left(x_{1 \imath}, x_{2 \imath}, x_{3 \imath}, \frac{\partial x_{1 \imath}}{\partial \lambda}, \frac{\partial x_{2 \imath}}{\partial \lambda}, \frac{\partial x_{3 \imath}}{\partial \lambda}\right)_{P_{j}} \\
=\left(x_{P \jmath}, y_{P \jmath}, 1, \cos (x \lambda)_{P \jmath}, \cos (y \lambda)_{P \jmath}, 0\right) \delta_{\imath \jmath}
\end{gathered}
$$

ここで $P_{j}=$ 第 $j$ 境界上の任意の点, その座標は $\left(x_{P J}\right.$, $\left.y_{P \jmath}\right), \delta_{\imath \jmath}=$ クロネッカーのデルタ, $\imath=1,2, \cdots \cdots, n$, $j=0,1,2, \cdots \cdots, n$

(c) 変形のくいちがいに関する条件領域内の $n$ 個の独立回路 $C_{\imath}(\imath=1,2, \cdots \cdots, n)$ に沿って回転 $\omega_{z}$ と変位 $u, v か ゙ 1$ 価であるための条件は

$$
\begin{aligned}
& \oint_{C_{\imath}}\left\{\frac{\partial}{\partial \nu},\left(y \frac{\partial}{\partial \nu}-x \frac{\partial}{\partial s}\right),\left(x \frac{\partial}{\partial \nu}+y \frac{\partial}{\partial s}\right)\right\}\left[\nabla ^ { 2 } \left\{X_{0}\right.\right. \\
& \left.\left.+\sum_{\imath=1}^{n}\left(C^{\prime}{ }_{1 \imath} x_{1 \imath}+C^{\prime}{ }_{2 \imath} x_{2 \imath}+C^{\prime}{ }_{3 \imath} x_{3 \imath}\right)\right\}+E \Lambda T\right] d s=0
\end{aligned}
$$

ここで $d s=$ 反時計方向に扔ける $C_{2}$ の弧長線素, $d \nu=$ $C_{\imath}$ の外向法線素

したがって(4)(5)式のもとに(3)式在解けば， $x_{0}, x_{12}$, $x_{2 \imath}, x_{3 \imath}$ が得られ，これを(6)式に代入して $C^{\prime}{ }_{1 \imath}, C^{\prime}{ }_{2 \imath}$, $C^{\prime}{ }_{3 \imath}$ を決定する. 所要の応力関数 $x$ は(2)式によって完 全に決定される.

\section{3 電気的相似法による熱応力関数の測定原理}

(3)式に招いて

$$
-E A \nabla^{2} T=q_{0}
$$

と和き,さらに

$$
\begin{aligned}
& \nabla^{2}\left(x_{0}, \quad x_{1 \imath}, x_{2 \imath}, x_{3 \imath}\right) \\
& \quad=\left(-M_{0},-M_{1 \imath},-M_{2 \imath},-M_{3 \imath}\right)
\end{aligned}
$$

と护くとき，(3)式は次の連立偏㸡分方程式に変換され る.

$$
\begin{aligned}
& \nabla^{2}\left(x_{0}, \quad x_{1 \imath}, \quad x_{2 \imath}, x_{3 \imath}\right) \\
& \quad=\left(\begin{array}{lll}
-M_{0}, & \left.-M_{1 \imath},-M_{2 \imath},-M_{3 \imath}\right)
\end{array}\right.
\end{aligned}
$$

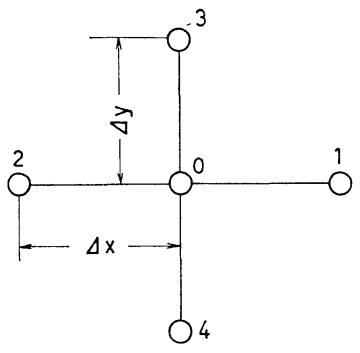

Fig. 2. Network pattern.

$\nabla^{2}\left(M_{0}, M_{1 \imath}, M_{2 \imath}, M_{3 \imath}\right)=\left(-q_{0}, 0,0,0\right)(10)$

(9)(10)式をFig. 2 の格子点 0 について階差表示を行な えば次の式をるる。

$$
\begin{gathered}
\frac{x_{0,1}+x_{0,2}-2 x_{0,0}}{\frac{\Delta x}{\Delta y}}+\frac{x_{0,3}+x_{0,4}-2 x_{0,0}}{\frac{\Delta y}{\Delta x}} \\
=-\Delta x \Delta y M_{0,0} \\
\frac{M_{0,1}+M_{0,2}-2 M_{0,0}}{\frac{\Delta x}{\Delta y}}+\frac{M_{0,3}+M_{0,4}-2 M_{0,0}}{\frac{\Delta y}{\Delta x}} \\
=-\Delta x \Delta y q_{0,0} \\
\frac{x_{\mathrm{mi}, 1}+x_{\mathrm{mi}, 2}-2 x_{\mathrm{mi}, 0}}{\frac{\Delta x}{\Delta y}}+\frac{x_{\mathrm{mi}, 3}+x_{\mathrm{mi}, 4}-2 x_{\mathrm{m} 1,0}}{\frac{\Delta y}{\Delta x}} \\
=-\Delta x \Delta y M_{\mathrm{m} 1,0} \\
\frac{M_{\mathrm{m} 1,1}+M_{\mathrm{m} 1,2}-2 M_{\mathrm{mi}, 0}}{\frac{\Delta x}{\Delta y}}+\frac{M_{\mathrm{m} 1,3}+M_{\mathrm{m} 1,4}-2 M_{\mathrm{m} 1,0}}{\frac{\Delta y}{\Delta x}} \\
=0
\end{gathered}
$$

ここで $m=1,2,3$

次に電気的シミュレーションを考觉るための Fig. 3 およびFig. 4 の抵抗回路網を作製して考慮する.各回

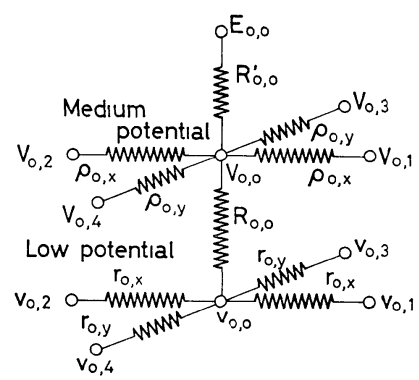

Fig. 3. Electrical network.

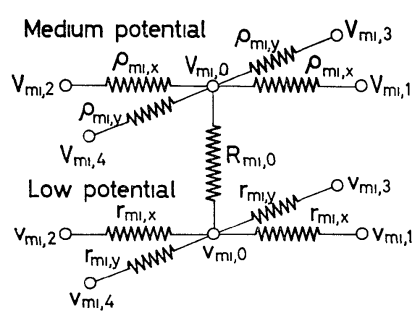

Fig. 4. Electrical network. 
路綃についてキルヒホッフの法則を適用すれば, Fig. 3 の低ポテンシァル格子網については

$$
\frac{v_{0,1}+v_{0,2}-2 v_{0,3}}{r_{0, x}}+\frac{v_{c, 3}+v_{0,4}-2 v_{0,0}}{r_{0, y}}=-\frac{V_{0,0}}{R_{0,0}}
$$

をえ，中ポテンシァル格子網については

$$
\begin{aligned}
\frac{V_{0,1}+V_{\mathrm{C}, 2}-2 V_{\mathrm{c}, 0}}{\rho_{0, x}} & +\frac{V_{0,3}+V_{\mathrm{c}, 4}-2 V_{0,0}}{\rho_{0, y}} \\
= & -\frac{E_{\mathrm{c}, 0}}{R_{0,0}^{\prime}}
\end{aligned}
$$

を5る。ただしそれぞれ $-v_{0,0} / R_{0,0}$ および $-V_{0,0} /$ $R_{0,0}^{\prime}-V_{0,0} / R_{0,0}+v_{0,0} / R_{0,0}$ を無視しうる程度に $r_{0, x}$, $r_{0, y}$ に比して $R_{0,0}$ が, $\rho_{0, x}, \rho_{0, y}$ に比して $R_{0,0}, R_{0,0}^{\prime}$ が大きいものとする.同様にして F1g. 4 に示す抵抗回 路網については次式をうる.

$$
\begin{aligned}
\frac{v_{\mathrm{m} 1,1}+v_{\mathrm{m} 1,2}-2 v_{\mathrm{m} 1,0}}{r_{\mathrm{m} 1, x}} & +\frac{v_{\mathrm{m} 1,3}+v_{\mathrm{m} 1,4}-2 v_{\mathrm{m} 1,0}}{r_{\mathrm{m} 1, y}} \\
= & -\frac{V_{\mathrm{mi}, 0}}{R_{\mathrm{m} 1,0}} \\
\frac{V_{\mathrm{m} 1,1}+V_{\mathrm{m} 1,2}-2 V_{\mathrm{m} 1,0}}{\rho_{\mathrm{m} 1, x}} & +\frac{V_{\mathrm{m} 1,3}+V_{\mathrm{m} 1,4}-2 V_{\mathrm{m} 1,0}}{\rho_{\mathrm{m} 1, y}} \\
= & 0
\end{aligned}
$$

換算係数 $l_{0},[\rho]_{0, c},[r]_{0, c},[R]_{0 c},\left[R_{-0, c}^{\prime}\right.$ および $l_{\mathrm{ml}},[\rho]_{\mathrm{mi}, c},[r]_{\mathrm{mi}, c},[R]_{\mathrm{m} 1, c}$ を考光て次の刘応を行 なう。

$$
\begin{aligned}
& \rho_{0, x}=\frac{\Delta x}{\Delta y}[\rho]_{0, c} \quad R_{0, n}=\frac{[R] \mathrm{c}, \mathrm{c}}{\Delta x \Delta y} \\
& \rho_{0, y}=\frac{\Delta y}{\Delta x}[\rho]_{0, c} \quad R_{0, n}^{\prime}=\frac{\left[R^{\prime}\right]_{0, c}}{\Delta x \Delta y} \\
& r_{0, x}=\frac{\Delta x}{\Delta y}[r]_{0, c} \quad v_{0, n}=l_{0} X_{0, n} \\
& r_{0, y}=\frac{\Delta y}{\Delta x}[r]_{0, c} \quad V_{0, n}=l_{0} M_{0 . n} \frac{[R]_{0, c}}{[r]_{0, c}}
\end{aligned}
$$

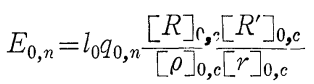

$$
\begin{aligned}
& \rho_{\mathrm{m} 1, x}=\frac{\Delta x}{\Delta y}[\rho]_{\mathrm{m} 1, c} \quad R_{\mathrm{m} 1, n}=-\frac{[R]_{\mathrm{mi}, c}}{\Delta x \Delta y} \\
& \rho_{\mathrm{m} 1, y}=\frac{\Delta y}{\Delta x}[\rho]_{\mathrm{m} 1, c} \quad v_{\mathrm{m}_{1}, n}=l_{\mathrm{m} 1} X_{\mathrm{m} 1, n} \\
& \left.r_{\mathrm{m} 1, x}=\frac{\Delta x}{\Delta y}[r]_{\mathrm{m} 1, c} \quad V_{\mathrm{m} 1, n}=l_{\mathrm{m} 1} M_{\mathrm{m} 1, n} \frac{[R]_{\mathrm{m} 1, c}}{[r}\right]_{\mathrm{m} 1, c} \\
& r_{\mathrm{m} 1, y}=\frac{\Delta y}{\Delta x}=[r]_{\mathrm{mi}, c} \\
& \text { ここで } n=0,1,2, \cdots \cdots, n
\end{aligned}
$$

(15)式を(13) (13) 式に，(15)' 式を(14) (14)'式に代入すれば,

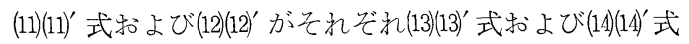
に対応することがわかる。これは(3) 式がFig. 3，4の 抵抗回路網によって近似的に相似解析されうることを 示すものである。

*1 F1g 3 亿扔いて負荷される百数十Vの電圧に対して，Fig 3 お よひ $F_{1} g \quad 4$ の格子網において抵抗 $\rho$ によって構成された回路 網には数 $\mathrm{V}$ の電流か, 抵抗 $ル$ にって構成された回路網には数 $\mathrm{mV}$ の電流が流れるように回路を構成したのて，それそ机中ポテ ンシァル格子網，低ポテンシァル格子網というととにした。
次に(4)(5)式に(15) (15)'式老代入すれば，次の電気系の 境界条件の式が壳られる。

$$
\begin{gathered}
\left(v_{0}\right)_{P_{\jmath}}=\left(\frac{\partial v_{0}}{\partial \lambda}\right)_{P_{\jmath}}=0 \\
\left(v_{1 \imath}, v_{2 \imath}, \quad v_{3 \imath}, \frac{\partial v_{1 \imath}}{\partial \lambda}, \frac{\partial v_{2 \imath}}{\partial \lambda}, \frac{\partial v_{3 \imath}}{\partial \lambda}\right)_{P_{\jmath}} \\
=\left(l_{1 \imath} x_{P_{\jmath}}, l_{2 \imath} y_{P_{\jmath}}, l_{3 \imath}, \quad l_{1 \imath} \cos (x \lambda)_{P_{\jmath}},\right. \\
\left.l_{2 \imath} \cos (y \lambda)_{P_{\jmath}}, 0\right) \delta_{\imath \jmath}
\end{gathered}
$$

したがって $x_{0}$ を求めるためには Fig. 3 のような回 路網を組丈， $x_{1 \imath}, x_{2 \imath}, x_{3 \imath}$, 老求めるためには Fig. 4 のような回路網を組み，それぞれ(16) (17) 式を満足する $v_{0}, v_{1 \imath}, v_{2 \imath}, v_{3 \imath}$ を求めればよいことがわかる。

\section{4 丸型鋼塊鋳型の熱応力}

計算例としてFig. 5 に示すような丸型鋼塊用鋳型に 造塊時に発生する熱応力を平面ひずみ問題として解析 した。丸型鋼塊用鋳型は厚肉円筒と考えるとき，これ に発生する熱応力の理論解は容易に求められるもので あり，Fig. 5 の鋳型はFig. 6 に示す理論解からもわか るように, 初期割れの起こることほほとんどない鋳型 であるが，電気的相似法の精度を檢討するため，この

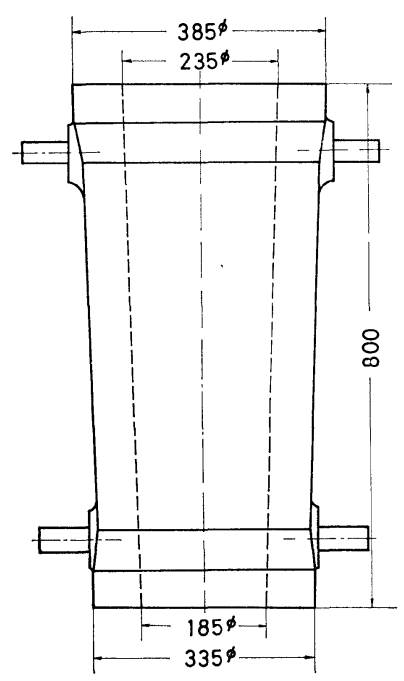

Fig. 5. Ingot mould

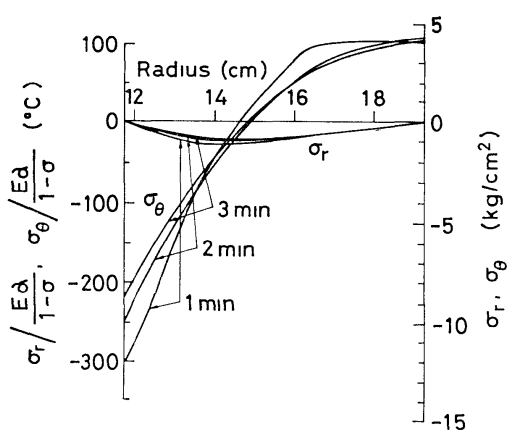

F1g 6 Distribution of thermal stress through wall of mould. 
鋳型の熱応力を求め理論解と比較した。

\section{$4 \cdot 1$ 温度分布}

温度分布は中心軸に対して対称であると考えて，軸 対称 1 次元問題として, 抵抗コンテンサー回路網によ って相似解析した．浴鋼鋳込 1 分後の温度分布， $\partial T /$ $\partial t$ 分布をFig. 7 に示す.

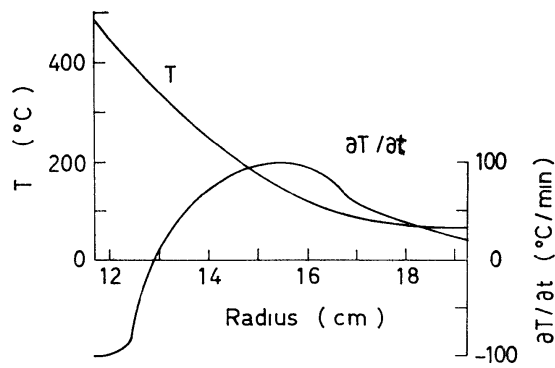

Fig. 7. Distribution of $\vec{I}$ and $\partial T / \partial t$ through wall of mould at $1 \mathrm{~min}$ after casting.

\section{$4 \cdot 2$ 応力分布}

\section{$4 \cdot 2 \cdot 1$ 応力分布の抵抗回路網による相似解法}

温度分布を中心軸に対して対称であると考えているの で，応力分布も中心軸に対して対称であると考学られ， この場合の基礎式は次のようになる。

応力成分は応力関数を $X$ とて次のよ5に与えられ る。

$$
\sigma_{r}=\frac{1}{r} \frac{d x}{d r}, \quad \sigma_{\theta}=\frac{d^{2} \chi}{d r^{2}}, \quad \tau_{r \theta}=0
$$

この $x$ は次の式で与光られる。

$$
x=x_{0}+C_{31}^{\prime} x_{31}
$$

(19)式の $x_{0}, x_{31}, C^{\prime}{ }_{31}$ は次の条件で決定される.

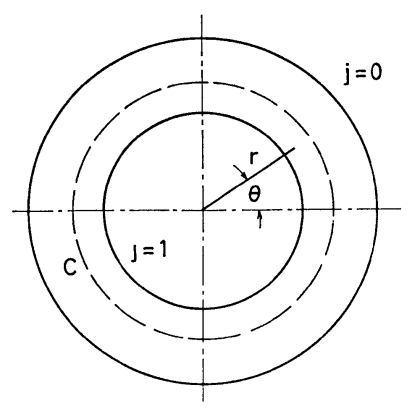

Fig. 8. Cylindrical region.

(a) 領域内の任意点について基礎式は

$$
\nabla^{4}\left(x_{0}, x_{31}\right)=\left(-\frac{E \alpha \nabla^{2} T}{1-\sigma}, 0\right)
$$

$$
\text { たたし } \quad \nabla^{2}=\frac{1}{r} \frac{d}{d r}\left(r \frac{d}{d r}\right)
$$

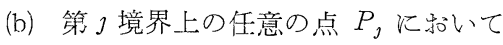

$$
\left(x_{0}, x_{31}, \frac{d x_{0}}{d r}, \frac{d x_{31}}{d r}\right)_{P_{\jmath}}=(0,1,0,0) \delta_{\imath \jmath}
$$

また $C^{\prime}{ }_{31}$ 性领域内の 1 周回路 $C$ に沿って, 回転 $\omega_{z}$ と
変位 $u, v か ゙ 1$ 価であるための条件により，次の式で 与光られ。

$$
C^{\prime}{ }_{31}=\frac{-\frac{d}{d r}\left(\nabla^{2} \chi_{0}\right)-\frac{E \alpha}{1-\sigma}\left(\frac{d T}{d r}\right)}{\frac{d}{d r}\left(\nabla^{2} x_{31}\right)}
$$

い屯

$$
\nabla^{2}\left(x_{01}, x_{31}\right)=\left(-M_{0},-M_{31}\right)
$$

と括き,さらに(7)式を用いるとき, (20)式は次の連立微 分方程式に変換される.

$$
\begin{gathered}
\nabla^{2}\left(x_{0}, x_{31}\right)=\left(-M_{0},-M_{31}\right) \\
\nabla^{2}\left(M_{0}, M_{31}\right)=\left(\begin{array}{ll}
-q_{0}, & 0
\end{array}\right)
\end{gathered}
$$

これをFig. 9 の格子点 $m$ について階差表示すれば次式 をうる。

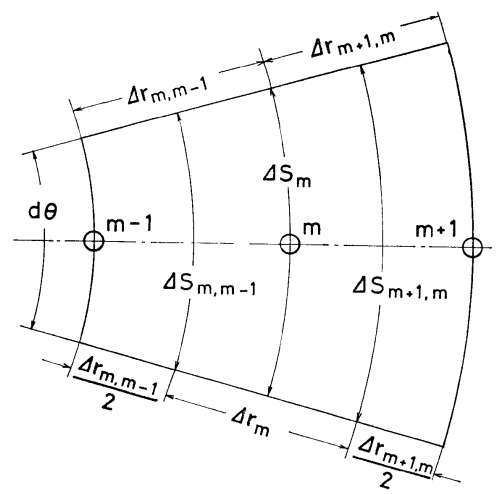

Fig. 9. Network pattern.

$$
\begin{aligned}
& \frac{\chi_{0, m+1}-\chi_{0, m}}{\frac{\Delta r_{m+1, m}}{\Delta s_{m+1, m}}}+\frac{\chi_{0, m-1}-\chi_{0, m}}{\frac{\Delta r_{m, m-1}}{\Delta s_{m, m-1}}}=-\Delta s_{m} \Delta r_{m} M_{0, m} \\
& \frac{M_{0, m+1}-M_{0, m}}{\frac{\Delta r_{m+1, m}}{\Delta s_{m+1, m}}}+\frac{M_{0, m-1}-M_{0, m}}{\frac{\Delta r_{m, m-1}}{\Delta s_{m, m-1}}}=-\Delta s_{m} \Delta r_{m} q_{0, m} \\
& \frac{\chi_{31, m+1}-x_{31, m}}{\frac{\Delta r_{m+1, m}}{\Delta s_{m+1, m}}}+\frac{\chi_{31, m-1}-\chi_{31, m}}{\frac{\Delta r_{m, m-1}}{\Delta s_{m, m-1}}}=-\Delta s_{m} \Delta r_{m} M_{31, m} \\
& \frac{M_{31, m+1}-M_{31, m}}{\Delta r_{m+1, m}} \\
& \frac{\Delta s_{m+1, m}}{M_{31, m-1}-M_{31, m}}
\end{aligned}
$$

前節の (13) (13)' (14) (14) 式を軸対称の 極座標系について 書き直すと，Fig. 10 和よびFig. 11 の抵抗回路網を用 いて(28)(28)' (29) (29)'式となる.

$$
\begin{aligned}
& \frac{v_{0, m+1}-v_{0, m}}{r_{0, m+1, m}}+\frac{v_{0, m-1}-v_{0, m}}{r_{0, m, m-1}}=-\frac{V_{0, m}}{R_{0, m}} \quad \text { (28) } \\
& \frac{V_{0, m+1}-V_{0, m}}{\rho_{0, m+1, m}}+\frac{V_{0, m-1}-V_{0, m}}{\rho_{0, m, m-1}}=-\frac{E_{0, m}}{R_{0, m}^{\prime}}
\end{aligned}
$$

$\frac{v_{31, m+1}-v_{31, m}}{r_{31, m+1, m}}+\frac{v_{31, m-1}-v_{31, m}}{r_{31, m, m-1}}=-\frac{V_{31, m}}{R_{31, m}}$ (29)

$\frac{V_{31, m+1}-V_{31, m}}{\rho_{31, m+1, m}}+\frac{V_{31, m-1}-V_{31, m}}{\rho_{31, m, m-1}}=0$ 


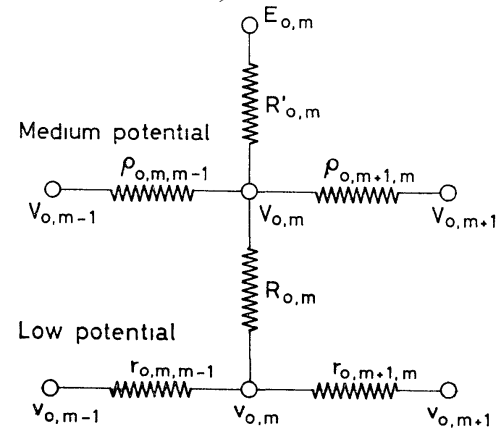

Fig. 10. Electrical networik.

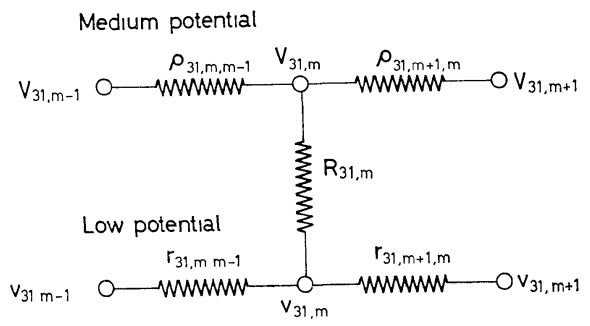

Fig. 11. Electrical network.

換算係数 $l_{0},[\rho]_{0, c},[r]_{0, c},[R]_{0, c},\left[R^{\prime}\right]_{0, c}$ 拈よび $l_{31},[\rho]_{31, c},[r]_{31, c},[R]_{31, \mathrm{c}}$ を考光て次の対応を行な 3 .

$$
\begin{gathered}
\rho_{0, m+1, m}=\frac{\Delta r_{m+1, m}}{\Delta s_{m+1, m}}[\rho]_{0, c} \quad v=l_{0} x_{0, m} \\
r_{0, m+1, m}=\frac{\Delta r_{m+1, m}}{\Delta s_{m+1, m}}[r]_{0, c} \quad V_{0, m}=l_{0} M_{0} \frac{[R]_{0, c}}{[r]_{0, c}} \\
R_{0, m}^{\prime}=\frac{\left[R^{\prime}\right]_{0, c}}{\Delta s_{m} \Delta r_{m}} \\
R_{0, m}=\frac{[R]_{0, c}}{\Delta s_{m} \Delta r_{m}} \\
E_{0, m}=l_{0} q_{0, m} \frac{\left[R^{\prime}\right]_{0, c}[R]_{0, c}}{[\rho]_{0, c}[r]_{0, c}} \\
\rho_{31, m+1, m}=\frac{\Delta r_{m+1, m}}{\Delta s_{m+1, m}}[\rho]_{31, c} \quad v_{31, m}=l_{31} x_{31, m} \\
r_{31, m+1, m}=\frac{\Delta r_{m+1, m}}{\Delta s_{m+1, m}}[r]_{31, c} \\
R_{31, m}=\frac{[R]_{31, c}}{\Delta s_{m} \Delta r_{m}} \\
V_{31, m}=l_{31} M_{31, m} \frac{[R]_{31, c}}{[r]_{31, c}}
\end{gathered}
$$

(28)(28)'式に(30)式を，(29)(29)'式に(30)式を代入すれば(26) (26) 式揖よび(27)(27)式をうる。これは(20)式が Fig. 10 およ び Fig. 11 の抵抗回路網によって近似的に相似解析さ れらることを示するのである。また(30)式沶上び(30)を
(21)式代代入すれば，応力系の境界条件は次の電気系の 境界条件汇変換される。

$$
\left(v_{0}, v_{31}, \frac{d v_{0}}{d r}, \frac{d v_{31}}{d r}\right)_{P_{\jmath}}=\left(0, l_{31}, 0,0\right) \delta_{\imath \jmath}
$$

したがって $x_{0}$ を求めるためには Fig. 12 の回路網 を， $x_{31}$ を求めるためには Fig. 13 の回路網を組及，

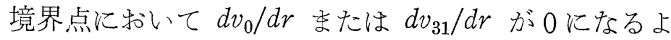
うに $V_{0}, V_{31}$ を調値して，各格子点に就ける $v_{0}$ また は $v_{31}$ を測定すればよい。

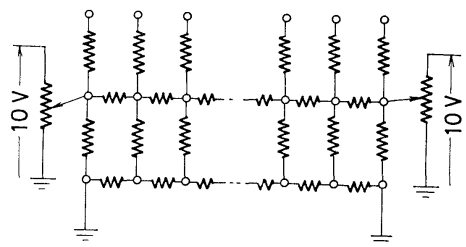

Fig. 12. Electrical network for $x_{0}$.

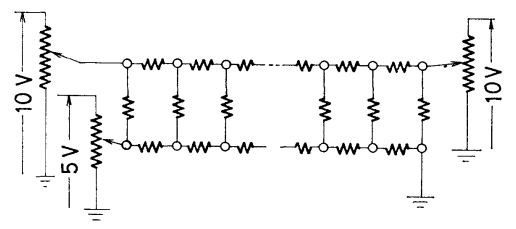

Fig 13. Electrical network for $x_{31}$.

つぎに $q_{0}$ を求めるためには熱伝導微分方程式から

$$
\nabla^{2} T=\frac{\rho C}{\lambda} \frac{\partial T}{\partial t}
$$

を光これを(7)式に代入して

$$
q_{0}=-\frac{E \alpha \rho C}{\lambda(1-\sigma)} \frac{\partial T}{\partial t}
$$

として求めた方が数值微分が 1 回で済み, 弪差が少な い.

$4 \cdot 2 \cdot 2$ 熱応力分布の解析 溶鋼鋳込後 1 分の応

\begin{tabular}{|c|c|c|c|c|c|c|c|c|c|c|c|c|}
\hline Mesh point & 0 & 1 & 2 & 3 & 4 & 5 & 6 & 7 & 8 & 9 & 10 & 11 \\
\hline$r(\mathrm{~cm})$ & 1175 & 1234460 & 1296930 & 1362560 & 1431512 & $\begin{array}{lll}15 & 03953\end{array}$ & 1580060 & 1660019 & $17 \quad 22632$ & 1787607 & 1855032 & 1925 \\
\hline
\end{tabular}
力分布を求めた。

（1）格子点 鋳型の内表面と外表面の間を11分割 した，各格子点の位置は Table I のと拈りである。

(2) 傾斜計算回路 (31)式法括る $d v_{0} / d r, d v_{31} / d r$ を測定するために固定抵抗で回路を構成した．

不等間隔格子に执いて $r=0$ 飞括沙る $f$ の傾斜はラ グランジュの内挿式から次のようとなる (Fig. 14).

$$
\begin{aligned}
\left(\frac{d f}{\partial r}\right)_{0}= & \frac{1}{a_{1} a_{2}\left(a_{1}+a_{2}\right)} \\
& \left\{\left(a_{1}+a_{2}\right)^{2} f_{1}-a_{2}\left(2 a_{1}+a_{2}\right) f_{0}-a_{1}^{2} f_{2}\right\}
\end{aligned}
$$

Fig. 15 に执いて

Table I Distribution of mesh point from center of mould. 
Table II. Value of resistance of electrical network.

\begin{tabular}{|c|c|c|c|c|c|c|c|c|c|c|c|c|}
\hline$m$ & 0 & 1 & 2 & 3 & 4 & 5 & 6 & 7 & 8 & 9 & 10 & 11 \\
\hline$o_{m-1, m}(\Omega)$ & & 200 & 200 & 200 & 200 & 200 & 200 & 200 & 75 & 75 & 75 & 75 \\
\hline$r_{m-1, m}(\Omega)$ & & 200 & 200 & 200 & 200 & 200 & 200 & 200 & 75 & 75 & 75 & 75 \\
\hline$R_{m}^{\prime} \quad(\mathrm{k} \Omega)$ & 1780 & 846 & 768 & 700 & 625 & 570 & 517 & 542 & 580 & 539 & 50 & 964 \\
\hline$R_{m} \quad(\mathrm{k} \Omega)$ & 7125 & 3385 & 3067 & 2778 & 2500 & 2294 & 2066 & 2167 & 2313 & 2157 & 200 & 3833 \\
\hline
\end{tabular}

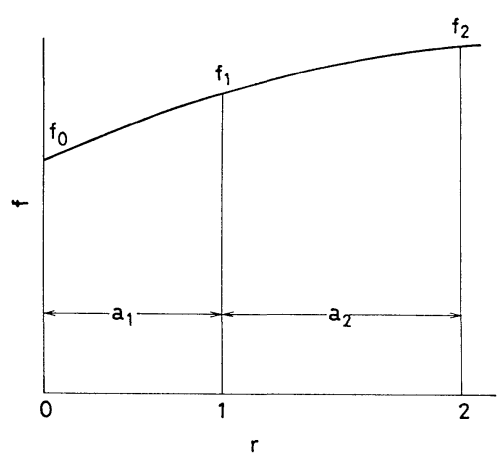

Fig. 14. Graphical representation of any function.

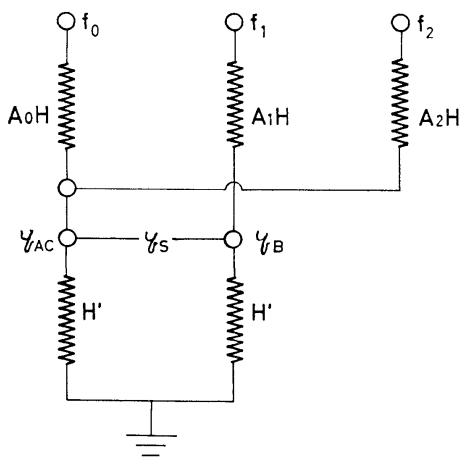

F1g. 15. Circuit for gradient.

$A_{0}=\frac{1}{a_{2}\left(2 a_{1}+a_{2}\right)}, \quad A_{1}=\frac{1}{\left(a_{1}+a_{2}\right)^{2}}, \quad A_{2}=\frac{1}{a_{1}^{2}}$ とすると

$$
\left(\frac{d f}{d r}\right)_{0}=\frac{1}{a_{1} a_{2}\left(a_{1}+a_{2}\right)}\left\{\frac{H}{H^{\prime}}+\left(a_{1}+a_{2}\right)^{2}\right\}\left(\eta_{B}-\eta_{A C}\right)
$$

か成立する．実際の計算では $H=200 \mathrm{k} \Omega, H^{\prime}=50 \mathrm{k} \Omega$ とした。

(3) 抵抗の設定値 計算回路の抵抗は $x_{0}$, およ び $x_{31}$ の計算に同じ価を用いた。 その設定值は Table II のと呿りであって，したがってその換算係数は Table III のと扮りになる。
Table III. Value of scale factor.

\begin{tabular}{c|c|c|c|c|c|c}
\hline$[\rho]_{0, \mathrm{c}}$ & {$[\rho]_{31, \mathrm{c}}$} & {$[r]_{0, \mathrm{c}}$} & {$[r]_{31, \mathrm{c}}$} & {$[R]_{0, \mathrm{c}}$} & {$[R]_{31, \mathrm{c}}$} & {$\left[R^{\prime}\right\rfloor_{0, \mathrm{c}}$} \\
\hline $200^{\Omega}$ & $200^{\Omega}$ & $200^{\Omega}$ & $200^{\Omega}$ & $\begin{array}{c}\mathrm{k} \Omega \mathrm{cm}^{2} \\
251506\end{array}$ & $\begin{array}{r}\mathrm{k} \Omega \mathrm{cm}^{2} \\
251506\end{array}$ & $\begin{array}{c}\mathrm{k} \Omega \mathrm{cm}^{2} \\
62877\end{array}$ \\
\hline
\end{tabular}

(4) $x_{0}$ の計算 (32) 式において $C=0.1 \mathrm{cal} / \mathrm{g}^{\circ} \mathrm{C}$, $\rho=7.27 \mathrm{~g} / \mathrm{cm}^{3}, \lambda=0.05 \mathrm{cal} / \mathrm{cms}^{\circ} \mathrm{C}$ とお活ば

$$
q=-0.24233 \frac{E \alpha}{1-\sigma} \frac{\partial T}{\partial t}
$$

となり，したかっって(30)式の第(7)式は次のようになる。

$$
E_{0, m}=-0.24233 \frac{E \alpha}{1-\sigma} l_{0} \frac{\left[R^{\prime}\right]_{0, c}[R]_{0, c}}{[\rho]_{0, c}[r]_{0, c}} \frac{\partial T}{\partial t} \quad \text { (36) }
$$

これに Table III の換算係数の価を代入すれば

$$
E_{0, m}=-0.958048 \times 10^{5} \frac{E \alpha}{1-\sigma} l_{0} \frac{\partial T}{\partial t} \quad \text { (37) }
$$

となる。これと前述の $\partial T / \partial t を$ 代入すれば各格子点 に特汀る電圧 $E_{0, m}$ が計算される。計算值には正負の 符号を含んだので，負の電圧の最大値が 0 になるよう に平行移動させ，平行移動させた等分布の負荷電圧に よる $v_{m}, V_{m}$ を測定値から差引いた。

換算係数 $l_{0}$ 在

$$
l_{0}=-10^{-5} \frac{1-\sigma}{E^{\alpha}}\left[\frac{V}{g}\right]
$$

とすることによって各格子点の $E_{0, m}$ の設定值はTable IV のようになる.

（5） $x_{31}$ の計算 $x_{31}$ の計算に括いては内側の境界 点に打ける電圧を $-20 \mathrm{mV}$ としたので，換算係数は (31)式から

$$
l_{31}=-20 \times 10^{-3}[\mathrm{~V} / \mathrm{g}]
$$

となる。

（6）前述のように設定された回路網によって求めら れた $\sigma_{r}, \sigma_{\theta}$ の洒を理論解と比較したものを Fig. 16 に示した、鋳型材質によって物性値をいかにとるかの 問題はあるが，図には $E \alpha /(1-\sigma)$ を $1 / 25 \mathrm{~kg} / \mathrm{mm}^{2 \circ}{ }^{4} \mathrm{C}^{4}$ とした尺度を付記した。

$$
5 \text { 結 }
$$

論

（1）理論解との比較から電気的相似法による平面熱

Table IV. Value of potential of high potential grid.

\begin{tabular}{c|c|c|c|c|c|c|c|c|c|c|c|c|c|c|c|c|c|c|c|c|}
\hline$m$ & 0 & 1 & 2 & 3 & 4 & 5 & 6 & 7 & 8 & 9 & 11 \\
\hline$E_{m}(v)$ & 0 & 435 & 110 & 150 & 177 & 194 & 192 & 175 & 155 & 137 & 127 & 120 \\
\hline
\end{tabular}




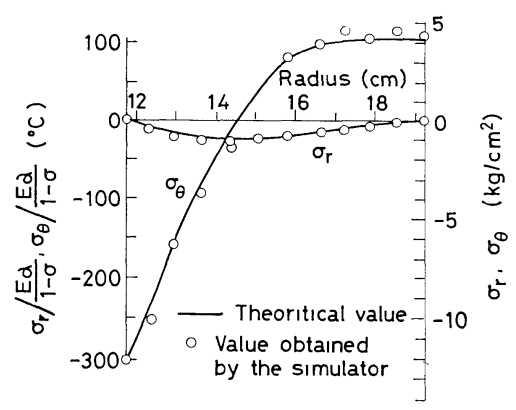

F1g. 16. Distribution of thermal stress through wall of mould.

応力問題の解析は相当㲏足すべき結果を与えるもので あることかわかる。しかし测定によって求まるものは 応力関数であって，これを数值微分して応力を求める 際に誤差が入ってくることが，上記の計算例の $\sigma_{\theta}$ が $\sigma_{r}$ より理論值との違いが大さいことから推定される.

（2）この方法によるとさは，格子点の数を増加すれ ば任意形状の重複連結領域の平面熱応力問題をも, そ
の形状にあうように抵抗回路網を組立てることによっ て解析することがでさる。

（3）この報告で行なった解析例では，境界条件は内 外両境界点の 2 点で満足されればよいにもかかわらず, その設定には相当回数の繰り返しを必要とした．2次 元問題においては隣接した境界上の格子点の影響をら 汁境界条件の設定はさらに困難になるものと思われる。 この点についてはさらに改良する必要がある。

\section{考文 献}

1) Palmer, P. J., and S.C. Redshaw, Aeron Quarterly, 6, 13 (1955).

2) Sekıya, $T$, and $Y$ Takeutı, Jap. Nat. Congr. Appl. Mech., 119 (1958).

3) Timoshenko, S., and J N Goodier, "Theory of Elasticity" Chap 14, McGraw-H111, Internation alstudent Edition.

4) 角誠之助, 日本穖械学会論文集, 34, 1378 (1968).

㫪

\section{新刊“CEMENT AND CONCRETE RESEARCH”誌紹介}

セメントとコンクリートに関する科学的研究は, 従来, 物理・化学・密業・土木・建築といろいろな専門雑誌 にばらばらに報告され，乙かも投稿から出版までに，一年以上を要するものが多かった。これを解決するため 3 年前東京で開催の第 5 回国際セメント化学シンポジウムの間に Della. M. Roy 教授の発案で新しい出版物の刊 行が相談され，この程，上記各分野の投稿論文を掲載した “CEMENT AND CONCRETE RESEARCH” 誌創 刊号が刊行された.ユニークな学術誌として今後の発展が期待される.

なお投稿は各著者が自分でタイプし，専門内容に応じ下記編集委員に送れば，査読後オフセット印刷される方 式をとっている.

SIR FREDERICK M. LEA.

PROFESSOR STEPHEN BRUNAVER

DR. R. ALEGRE

DR. Z.P. BAŽANT

DR. L.E. COPELAND

PROFESSOR W.L. DOLCH

DR. G. M. IDORN

DR. GEORGE L. KALOUSEK

PROFESSOR RENICHI KONDO

DR. R.G. L'HERMITE

PROFESSOR R.H. MILLS
DR. R. W. NURSE

PROFESSOR A. M. NEVILLE

MR. ROBERTE PHILLEO

DR. ZDENĚK ŠAUMAN

PROFESSOR HABIL. H. E. SCHWIETE

MR. P. J. SEREDA

DR. F.D. TAMÁS

PROFESSOR H.F.W. TAYLOR

DR. R. BRADY WILLIAMSON

DR. FOLKER H. WITTMANN

PROFESSOR GORO YAMAGUCHI

発行所 Pergamon Press Inc. (Headington Hill. Holl, Oxford, England)

購 読 料 個人 \$15（または £6）, 大学, 法人等 $\$ 30$ (または £12)

発行回数当分の間年 6 回 